\title{
Distinguishing Dialect and Development from Disorder: Case Studies
}

\author{
Barbara Zurer Pearson, Ph.D., ${ }^{1}$ and Lois Ciolli, M.A., C.C.C.-S.L.P. ${ }^{2}$
}

\section{ABSTRACT}

Seven case studies are presented to illustrate how the tasks in the proposed test battery provide the tools to distinguish language differences due to development or dialect from true signs of delay or disorder. The case studies exemplify different combinations of language strengths and weakness found among participants of extensive field research in the age range from 4 to 9 years. Special attention is paid to certain aspects of language development, such as time clauses or double wh-questions, in which dialect features play no role. All levels of performance, from the highest to the lowest, are found in children who are speakers of Mainstream American English (MAE) and the same is true for those whose language patterns indicate a strong variation from MAE.

KEYWORDS: Profile, path of progress, subdomain, item types, strength, weakness, interpretation

Learning Outcomes: As a result of this activity, the participant will be able to identify (1) how breaking down the items on the proposed diagnostic test into subtypes helps to profile the child's strengths and weaknesses, and (2) why it is vital to consider all three factors-development, dialect, and disorder-when evaluating a child's language.

First and foremost, the goal for a dialectsensitive language assessment is to help clinicians identify the signs of language disorder in children without penalizing them for dialect features or typical linguistic development. Some children will exhibit signs of all three factors (i.e., disorder, dialect, and develop- ment); others will exhibit just one or two signs in different combinations. The ideal assessment helps clinicians recognize when dialect features are present alone or in conjunction with signs of delayed or disordered development, and also when delay or disorder is apparent, but dialect features are not. As with all assessment

Evaluating Language Variation: Distinguishing Dialect and Development from Disorder; Editors in Chief, Nancy HelmEstabrooks, Sc.D., Nan Bernstein Ratner, Ed.D.; Guest Editors, Harry N. Seymour, Ph.D., and Barbara Zurer Pearson, Ph.D. Seminars in Speech and Language, volume 25, number 1, 2004. Address for correspondence and reprint requests: Barbara Zurer Pearson, Ph.D., Research Associate, Department of Communication Disorders, University of Massachusetts Amherst, Amherst, MA 01003. E-mail: bpearson@comdis.umass.edu. ${ }^{1}$ Research Associate, Department of Communication Disorders, University of Massachusetts Amherst, Amherst, Massachusetts; ${ }^{2}$ The Psychological Corporation, Harcourt Assessment, Inc., San Antonio Texas. Copyright (C) 2004 by Thieme Medical Publishers, Inc., 333 Seventh Avenue, New York, NY 10001, USA. Tel: +1(212) 584-4662. 0734-0478,p;2004,25,01,101,112,ftx,en;ss100186x. 
instruments, the results need to be considered along with all other information gathered about the child.

In this article, we explore the profiles of seven children from our field research to illustrate how the tasks in the proposed test battery provide the tools to make the required distinctions. The case study children were chosen to exemplify different combinations of strengths and weaknesses and different levels of dialect usage at different points in the age range 4 to 9 years. Two 4-year-old children are used to contrast typical versus delayed development. In addition, both speak with "Some Variation from Mainstream American English (MAE)," but contrast with respect to how the results of their Language Variation Status should be interpreted. The expectations for performance of a 4-year-old child are contrasted with those for a 9-year-old child, who shows relatively fewer errors, but more serious risk and/or disorder. Two 6-year-old children also illustrate the contrast between a diagnosis of disorder versus no disorder, and in addition show how our proposed assessment measure may reveal linguistic strengths in children in whom such strengths are less apparent-in the quiet child and in the child with a severe phonological disorder. Finally, two 7-year-old children illustrate the contrast between a nonMAE speaker with no disorder and a disordered child who speaks MAE. Ironically, the former is receiving language services, whereas the latter is not.

In these case studies, the dialect or Language Variation Status designations for each child are derived directly from our screening items, and further illustrated with examples taken from the child's answers to other items of the comprehensive language test in which the children's short-sentence answers were written verbatim on the record form by the examiner. The diagnostic risk designations come from the child's score on the second set of screening items.

\section{GENERAL GUIDE TO GROWTH BY SUBDOMAIN}

Summarizing across the tasks in the diagnostic portion of the screening test and the four domains of the proposed comprehensive language test, there are 14 item-types represented by the names of the subdomains on the record form: for example, fast mapping, short narrative, wh-question comprehension, and so on (see Fig. 1 in Seymour and Pearson ${ }^{1}$ ) Those subdomains are further subdivided at the itemtype level into target skills or concepts. Thus, the Syntax domain wh-questions are of three subtypes: double wh-questions, embedded false clauses, and barrier questions; the Articles subdomain has items of two subtypes, definite ("the") and indefinite ("a"). The Semantics domain fast mapping items can be viewed as two subtypes, real verbs and novel verbs, or as three subtypes across real and novel, according to whether the item involves transitive, transfer, or complement structures. In all, there are over 30 item-subtypes. (The subtypes and their rationales are discussed individually in the articles on the individual domains (Roeper, ${ }^{2}$ P. de Villiers, ${ }^{3}$ J. de Villiers, ${ }^{4}$ and Seymour ${ }^{5}$.)

For the various subdomains and item subtypes, there is a general path of progress, such as the ones outlined in Table 1 for wh-questions, Table 2 for short narratives, and Table 3 for nonword repetition (from the screener, part 2). There are also developmental graphs in the domain articles that provide similar growth ranges for many of the constructs in the various subdomains.

These growth ranges represent an approximate timeline to help evaluate the children's responses from a qualitative point of view. However, one cannot say a child is "functioning like a 4 year old" because he or she gave two of two medial answers, corresponding to the description for that construct under 4-year-old children in Table 1 . One must take several factors and more than one subdomain into account to make such a judgment. However, the tables indicate the nature of our expectation of progress as the child grows. Even though most 4-year-old children make errors in all four areas noted, only the weakest ones fail at all of them. For example, if a 4-year-old child passes the false clause items and the relative clause items, but makes medial and singleton errors on the other questions $\left(\right.$ Roeper $\left.^{2}\right)$, that would be an average or above-average four-year-old per- 


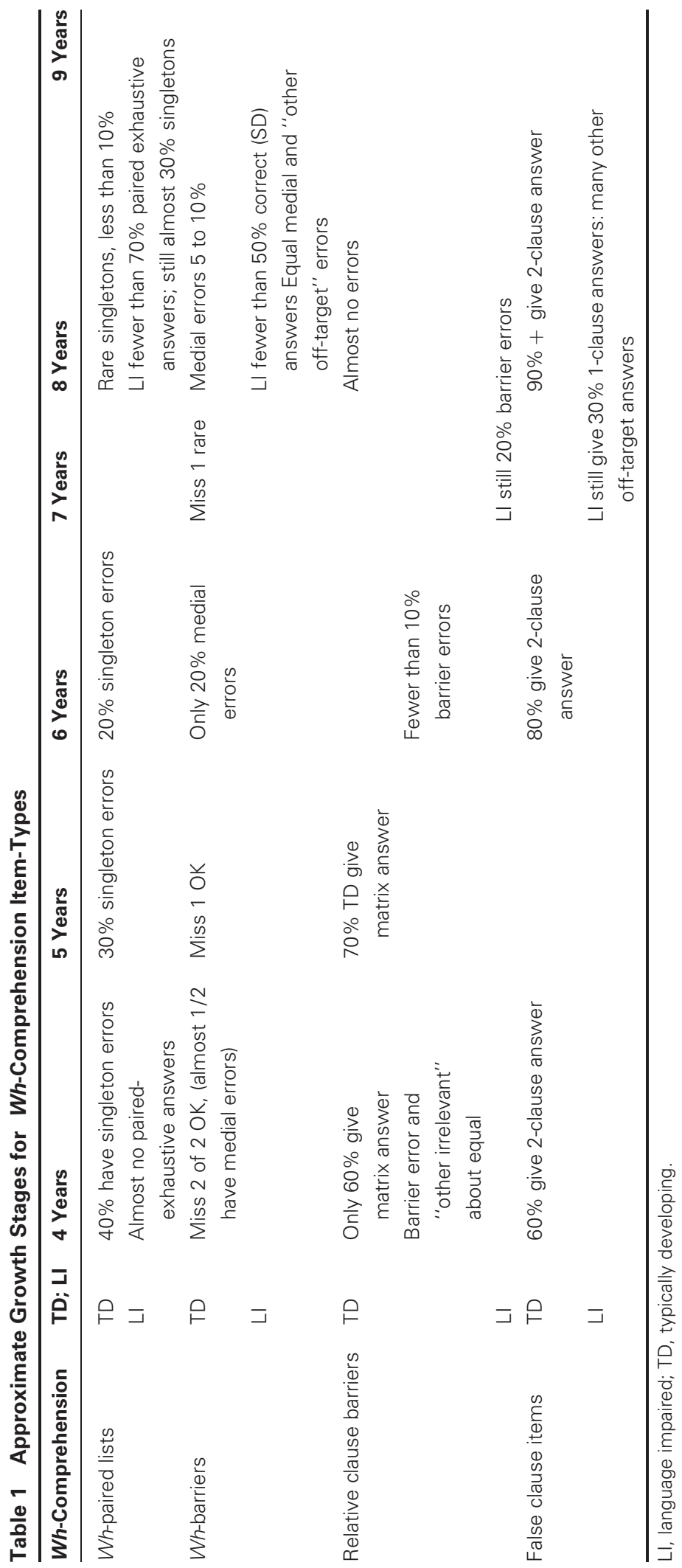




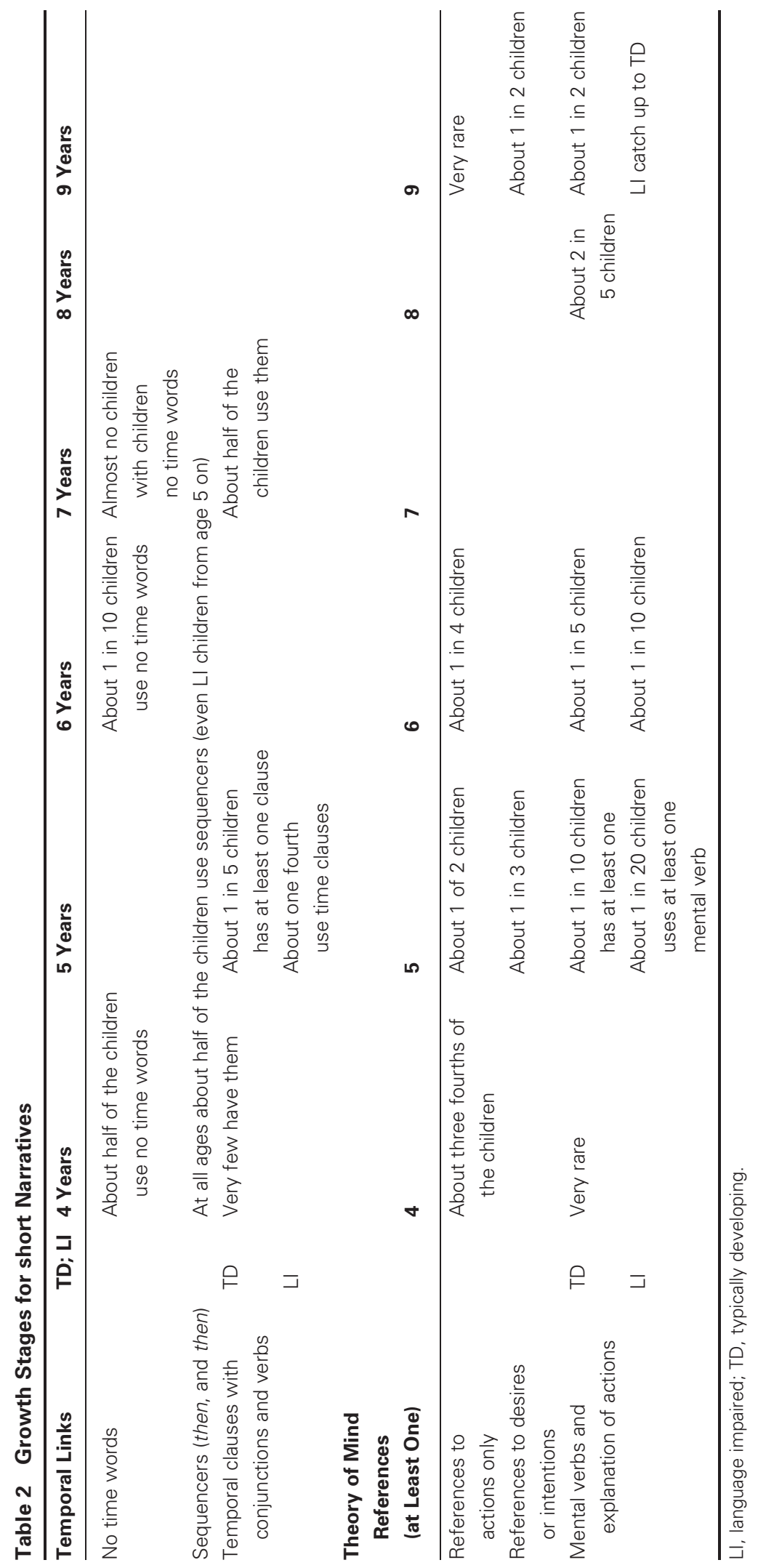


Table 3 Expectation for Errors in Nonword Repetition

\begin{tabular}{lll}
\hline 4-5 Years & $\mathbf{6 - 7}$ Years & 8-9 Years \\
\hline $\begin{array}{l}\text { Expect } 1 \text { to } 2 \text { errors on 3- and 4- } \\
\text { syllable prompts }\end{array}$ & $\begin{array}{l}\text { Expect 1 error on 4-syllable } \\
\text { prompt }\end{array}$ & Expect few errors \\
\hline
\end{tabular}

formance for the wh-question subdomain. A 6year-old child with the same set of answers would be below average, and if, for example, she or he gave all four double wh-questions as singleton answers, that alone would point to a low average or weak performance in that subdomain because 6-year-old children are expected to get at least some of the double whquestions correct. For a 9-year-old child, a single nonexhaustive (singleton) answer would be a warning signal. Keep in mind, however, that Table 1 presents only the average based on the sample reported by Roeper ${ }^{2}$; it does not present ranges of responses by age.

\section{THE CASE STUDIES}

The profile for a case study child makes reference first to an overall evaluation and a summary of scores by domain. To characterize what makes the child average or below or above in a domain, we comment on only some subdomains and item types-generally those that stand out as different from the kind of answers given by typically developing children of the same age or as different from other parts of the child's own performance. The case studies illustrate how scores on all four domains interact and help the clinician make recommendations for services (see discussion in Seymour and Pearson $\left.^{1}\right)$.

\section{DISTINGUISHING DEVELOPMENT FROM DIALECT}

\section{Case Study 1: Charnelle \\ (Age 4 years, 2 months)}

\section{PROBABLE CONTRIBUTING FACTORS}

Developmental: Yes

Dialectal: Yes

Disordered: No

Charnelle (Table 4) is a typically developing 4-year-old African American child whose speech and language was screened upon her entrance into prekindergarten in the neighborhood public school. She is the youngest member of a large family in the midwest. Her parents are high school graduates and both are employed outside the home.

\section{DEVELOPMENTAL VARIATION}

As presented in Table 4, Charnelle scored in the "Some Variation from MAE" range on the proposed Language Variation Status items and showed medium risk on the diagnostic portion of the screening test, so the dialect-sensitive comprehensive language test was the recommended follow-up.

As expected because of her young age, Charnelle shows a mixture of strengths and weaknesses. These developmental variations

Table 4 Charnelle (4 years, 2 months)-Summary of Scores

\begin{tabular}{|c|c|c|c|c|c|}
\hline \multicolumn{2}{|c|}{ Screening Items } & \multicolumn{4}{|c|}{ Comprehensive Language Test } \\
\hline $\begin{array}{l}\text { Language } \\
\text { Variation } \\
\text { Status }\end{array}$ & $\begin{array}{l}\text { Diagnostic } \\
\text { Risk } \\
\text { Status }\end{array}$ & Syntax & Pragmatics & Semantics & Phonology \\
\hline $\begin{array}{l}\text { Some variation } \\
\text { from MAE }\end{array}$ & $\begin{array}{l}\text { Medium risk } \\
\text { for disorder }\end{array}$ & $\begin{array}{l}17 \\
\text { Average }\end{array}$ & $\begin{array}{l}12 \\
\text { Average }\end{array}$ & $\begin{array}{l}24 \\
\text { Average }\end{array}$ & $\begin{array}{l}20 \\
\text { Average }\end{array}$ \\
\hline
\end{tabular}

MAE, Mainstream American English. 
are mixed with dialectal variations due to the influence of the language spoken most often in her home and community (i.e., African American English [AAE]). For example, she produced the "th" sound as $[\mathrm{f}],[\mathrm{v}]$, or $[\mathrm{d}]$ in predictable AAE contexts (e.g., "mouf" and "wiv" for "with," and "anoder" for "another"). Like many young MAE and AAE 4-yearold children, Charnelle finds "th" difficult to produce in other contexts not associated with dialect differences, such as "frowing" for "throwing." She also still is having trouble pronouncing the /r/ and /1/ sounds in words such as "play" ("pway") and "cracker" ("kwacker"), so her speech contains some typical developmental errors.

This combination of development and dialect also is seen in her morphosyntax items: she gave several MAE responses in the identifier section (part 1) of the screening items, in possessive and auxiliary verb items, and some predictable dialect responses as well. This mixture of MAE/non-MAE responses earned her a dialect score of "Some (but not strong) Variation from MAE." When she was responding to items on the comprehensive language test, the examiner noted that Charnelle used single negation (e.g., "has no shoes"; an MAE feature) three times and multiple negation (e.g., "don't have no shoes"; a feature characteristic of AAE) only once. Throughout both the screening and diagnostic tests, Charnelle gave many responses that could only be classified as "other;" most of them were incomplete answers or answers that indicated that she did not understand the target of the items. In pragmatics question asking, like many of the 4-year-old children, she had difficulty suppressing the temptation to answer rather than ask questions, and she reached her ceiling early.

Despite such answers that show her developing status, in several subdomains of the comprehensive language test, she responded with surprising maturity. In the short narratives, Charnelle contrasted the characters and used time sequencers; she understood the importance of "thought balloons" in the pictures and reported what the characters were dreaming about and what they wanted, instead of focusing only on actions or descriptions of the pictures, which is more typical of a child her age. In wh-questions, she also gave answers unusual at her age: she got all three double wh-questions correct, giving exhaustive, paired responses ("she caught the crab with a net and a fish with her pole," [see Roeper ${ }^{2}$ ]), and she responded correctly to the complex question about what "the sister said she brought." In the passive and quantifier subdomains, she also had a combination of both very strong and very weak performances.

\section{SUMMARY}

Both dialect and developmental influences are seen in Charnelle's test performance. Although she appeared to be at some risk for a language disorder (i.e., she showed medium risk on the screener), she passed the comprehensive test, scoring in the average range in all four domains. She illustrates how the two tests taken together help distinguish which features are due to development and dialect. In Charnelle's case, a diagnosis of disorder does not appear warranted.

\section{Case Study 2: Carla (Age 4 years, 0 months)}

\section{PROBABLE CONTRIBUTING FACTORS:}

Developmental: Yes

Dialectal: No

Disordered: Yes

Carla (Table 5) is a non-Hispanic white child in a Head Start program in the northeastern United States. She was screened as part of Head Start's routine program. Both of her parents have completed high school. Although the mother works part time outside the home, she also volunteers 1 day a week at Carla's preschool.

Like Charnelle, Carla's Language Variation Status is in the "Some Variation from MAE" range. Because there is no indication that she is from a minority community, there is no reason to attribute this score to dialect background. It is more likely the consequence of delayed development or disorder. That is, her variation from MAE may be caused by more off-target responses as well as some remnants of immature language in her speech. Her 
Table 5 Carla (4 years, 0 months) -Summary of Scores

\begin{tabular}{|c|c|c|c|c|c|}
\hline \multicolumn{2}{|c|}{ Screening Items } & \multicolumn{4}{|c|}{ Comprehensive Language Test } \\
\hline $\begin{array}{l}\text { Language } \\
\text { Variation } \\
\text { Status }\end{array}$ & $\begin{array}{l}\text { Diagnostic } \\
\text { Risk } \\
\text { Status }\end{array}$ & Syntax & Pragmatics & Semantics & Phonology \\
\hline $\begin{array}{l}\text { Some variation } \\
\text { from MAE }\end{array}$ & Highest & $\begin{array}{l}15 \\
\text { Low }\end{array}$ & $\begin{array}{l}5 \\
\text { Weakness }\end{array}$ & $\begin{array}{l}18 \\
\text { Low }\end{array}$ & $\begin{array}{l}18 \\
\text { Average }\end{array}$ \\
\hline
\end{tabular}

MAE, Mainstream American English.

phonology, although in the average range, still has several poorly articulated consonants, mostly distortions. We also see in her verbatim responses terms such as "has an owee" and "a boo-boo." However it is her high Diagnostic Risk Status that suggests that her overall language development is slower than that of her peers. Carla's performance on the comprehensive language test shows her to be in the low average and weakness score category in three of the four language domains. In a few subdomains she is showing age-appropriate progress, but there are several in which she shows serious problems. In no subdomain does she show strength.

The examiner noted that although Carla was pleasant and cooperative in the test session, she had difficulty with almost all of the directions. In question asking, when told to "Ask me a 'what' question," she merely repeated the words, "a what question;" similarly, she repeated "a who question." In short narratives, her answers to the follow-up questions were offtarget. For example, when asked, "Why was she looking there?" (with emphasis on "there"), Carla did not focus on the character's choice of a place to look as the contrastive stress directs the child to do. Instead she told the examiner why the girl wanted the item she was looking for ("cause she's going to throw it in the garbage"). Although her response is not completely unrelated, there is nothing in the pictures to suggest such an idea, so it looks like she is not interpreting the prompt and is falling back on her nonverbal interpretations of the pictures.

\section{Case Study 3: Dominique (Age 9 years, 11 months)}

\section{PROBABLE CONTRIBUTING FACTORS}

Developmental: No

Dialectal: Yes

Disordered: Yes

Dominique (Table 6) is an African American 9-year-old child in third grade in a small town in the south. He has been receiving language services for 1 year on the basis of previous testing. Because there was some question as to the validity of the previous testing, Dominique was given the dialect-sensitive test battery described in this issue (Screening and Comprehensive Language Test) to confirm his continued eligibility.

Because he is 9 , at the upper end of the age range, he gets many responses correct. A few "red flags," or crucial errors, however, are enough to confirm his high risk status on

Table 6 Dominique (9 years, 11 months)-Summary of Scores

\begin{tabular}{|c|c|c|c|c|c|}
\hline \multicolumn{2}{|c|}{ Screening Items } & \multicolumn{4}{|c|}{ Comprehensive Language Test } \\
\hline $\begin{array}{l}\text { Language } \\
\text { Variation } \\
\text { Status }\end{array}$ & $\begin{array}{l}\text { Diagnostic } \\
\text { Risk } \\
\text { Status }\end{array}$ & Syntax & Pragmatics & Semantics & Phonology \\
\hline $\begin{array}{l}\text { Strong variation } \\
\text { from MAE }\end{array}$ & $\begin{array}{l}\text { Medium to high } \\
\text { risk for disorder }\end{array}$ & $\begin{array}{l}25 \\
\text { Weakness }\end{array}$ & $\begin{array}{l}21 \\
\text { Average }\end{array}$ & $\begin{array}{l}33 \\
\text { Weakness }\end{array}$ & $\begin{array}{l}25 \\
\text { Strength }\end{array}$ \\
\hline
\end{tabular}

MAE, Mainstream American English. 
the screening test and predict his areas of "weakness" on the comprehensive language test. For example, Dominique's medial answer to a wh-barrier item raises a question. Although some typically developing 9-year-old children $(\sim 10 \%)$ are still consolidating their ability to interpret those questions and will miss one from time to time, Dominique missed all of the double wh-questions. Fewer than 1 in 10 typically developing children of his age would give even one singleton answer (see Table 1). Another strong indicator is found in the quantifier subdomain on one of the every items. Dominique's answer shows he extends every to all of the elements in the picture, rejecting the statement about "every cat" because there's a rabbit doing something else. This is a very common (40\%) error among 5-year-old children, but this type of error occurs much less frequently by age 8 years-except among language-impaired children (Table 6).

The examiner also noted other behavioral signs of Dominique's language difficulties. Instead of answering, he repeated one of the prompts in the preposition contrasts items, and three times he repeated his first answer to verb contrast items, despite being prompted to "tell me a different word, not one you've already said." This indicates that he is having difficulty organizing his lexicon so that it can be used flexibly and appropriately.

\section{SIX-YEAR-OLD CHILDREN: DISCOVERING COMPETENCIES WITH THE PROPOSED TESTS}

To be average at age 6 requires a higher percentage of correct answers than at age 4 , but there is still room for some unevenness in a child's performance. The picture in all domains taken together must be considered. Failure in one domain gives the clinician or teacher suggestions for areas that may need special attention, but weakness in one domain does not indicate, by itself, disorder.

\section{Case Study 4: Serina (Age 6 years, 0 months)}

\section{PROBABLE CONTRIBUTING FACTORS}

Developmental: No

Dialectal: Yes

Disordered: No

Serina (Table 7) is an African American 6year-old child in a suburban public school in a racially mixed neighborhood in the western region of the United States. Her father has a college degree and her mother has some college background as well. According to the first set of screening items, Serina speaks with a strong variation from MAE. Although her responses on part II put her in a low-risk category, she is one of the youngest children in her first grade class and she rarely speaks up in class. Because of her teacher's concern, she was evaluated further with the comprehensive language test.

Serina failed (scored in the weakness category) in the Semantics domain. Indeed, her weakness in three of the four subdomains of Semantics may have been what alerted her teacher to a possible problem. However, in all other areas tested, Serina's scores were average or above and provide evidence of her adequate language abilities overall.

Serina's lowest score relative to her peers was in verb contrasts, where she missed 7 of 10 items. However, she did not make the most immature kinds of errors, such as repeating a prompt or giving the same answer to two

Table 7 Serina (6 years, $\mathbf{0}$ months)-Summary of Scores

\begin{tabular}{|c|c|c|c|c|c|}
\hline \multicolumn{2}{|c|}{ Screening Items } & \multicolumn{4}{|c|}{ Comprehensive Language Test } \\
\hline $\begin{array}{l}\text { Language } \\
\text { Variation } \\
\text { Status }\end{array}$ & $\begin{array}{l}\text { Diagnostic } \\
\text { Risk } \\
\text { Status }\end{array}$ & Syntax & Pragmatics & Semantics & Phonology \\
\hline $\begin{array}{l}\text { Strong variation } \\
\text { from MAE }\end{array}$ & Lowest & $\begin{array}{l}26 \\
\text { Average }\end{array}$ & $\begin{array}{l}21 \\
\text { Strength }\end{array}$ & $\begin{array}{l}24 \\
\text { Weakness }\end{array}$ & $\begin{array}{l}22 \\
\text { Average }\end{array}$ \\
\hline
\end{tabular}

MAE, Mainstream American English. 
different prompts. Examination of the answers she gave showed that she had difficulty matching the contrast of the prompt, giving too specific a word three times and too general a word three other times. In quantifiers she also had difficulty with comprehending a precise word meaning. She showed that she did not yet understand the meaning of every, much less have an appreciation of its special properties (as discussed by J. de Villiers ${ }^{4}$ ). In her fast mapping, she did better with the real verbs than the novel verbs, indicating that she may be relying on lexical cues, and not taking as much information as she could from the structure of the sentences she hears.

In contrast to her performance in Semantics, Serina scored above average in the Pragmatics domain. She was particularly good in recognizing the false belief of the character in the short narrative and in using the language of thought to describe the motivations for events in the story. In her question asking, she needed a second prompt for almost all of the items, but with a little extra guidance demonstrated her competence at recognizing what she did not know and asking the appropriate question to learn it. In both of these subdomains she demonstrated not only that she understood what she was shown, but also that she was adept at using what was stated to find out more.

\section{Case Study 5: Leon (Age 6 years, 4 months)}

\section{PROBABLE CONTRIBUTING FACTORS}

Developmental: Yes

Dialectal: Yes

Disordered: Yes (but with unexpected strengths)
This case study illustrates a situation in which the child's unintelligibility makes accurate diagnosis difficult. Leon (Table 8) is a 6-year-old African American child who lives with his mother in a northern city. Leon's mother has less than a high school education. Like Serina, Leon also failed the Semantics domain and excelled in the Pragmatics domain, but there the similarity ends. He is repeating kindergarten, and both he and his teacher are having a difficult time. Leon's speech errors are so severe that he is almost impossible to understand. The screener confirmed that Leon substitutes final consonants and simplifies clusters in a way consistent with an AAE dialect, but the results of the Phonology domain show that his variation in his speech goes far beyond dialect difference and that he would profit from a full phonological evaluation. Almost one third of the words he produced on the Phonology domain had at least one consonant that was so distorted that the examiner could not transcribe it. Furthermore, he simplified initial clusters, as a younger child might, but in addition, he omitted initial consonants. This pattern is very damaging to intelligibility and is not characteristic of either dialect differences or typical developmental patterns.

Given the obvious nature of his problem, Leon had already been diagnosed with a phonological and language disorder before he was given our assessment items, and he was already scheduled to begin receiving them. The speechlanguage pathologist gave him the experimental probes to help identify therapy goals for him. In Leon's case, the innovative items were useful in showing unexpected strengths.

On part II of the screening items, Leon omitted almost all of the past tense copulas ("was") and did not even attempt the threeand four-syllable prompts in the nonword

Table 8 Leon (6 years, 4 months)-Summary of Scores

\begin{tabular}{|c|c|c|c|c|c|}
\hline \multicolumn{2}{|c|}{ Screening Items } & & \multicolumn{3}{|c|}{ Comprehensive Language Test } \\
\hline $\begin{array}{l}\text { Language } \\
\text { Variation } \\
\text { Status }\end{array}$ & $\begin{array}{l}\text { Diagnostic } \\
\text { Risk } \\
\text { Status }\end{array}$ & Syntax & Pragmatics & Semantics & Phonology \\
\hline $\begin{array}{l}\text { Strong variation } \\
\text { from MAE }\end{array}$ & Highest & $\begin{array}{l}20 \\
\text { Weakness }\end{array}$ & $\begin{array}{l}20 \\
\text { Strength }\end{array}$ & $\begin{array}{l}20 \\
\text { Weakness }\end{array}$ & $\begin{array}{l}5 \\
\text { Weakness }\end{array}$ \\
\hline
\end{tabular}

MAE, Mainstream American English. 
repetitions. On the comprehensive language test he showed very weak performance on articles, preposition contrasts, and fast mapping. In all of these areas, successful performance depends on good comprehension of short, unstressed elements in the stream of speech. To succeed at fast mapping, for example, the child must attend closely to the endings of words (such as the -er, -ing, and -ible endings). These all appear to be compromised in Leon's language system.

However, as noted above, Leon showed strength in Pragmatics. In particular, he got all but the double $w h$-question correct in question asking, which is unusually good for a 6-year-old child. Although his utterances lacked the unstressed elements, which caused him difficulty in other parts of the test (such as, "Why she so mad?" and "Who cake there?" for "Whose cake is in there?"), he was above average in his understanding of the communicative needs in the scenarios presented. Similarly, in the short narrative, he recognized and articulated that the cake was moved and so the character who did not see it being moved would not know where it was. In the field research, only about one in five 6-year-old children showed this high level of understanding. Finally, his wh-question comprehension was also above the expected level for typically developing children his age. He gave a singleton answer one time where a paired exhaustive answer was expected (see Roeper ${ }^{2}$ ), but that was his only error. He got the other paired exhaustive answer right and both barrier questions. Consistent with his mature "theory of mind" answers in short narrative, Leon also correctly responded to the item that assesses a child's comprehension of complements with a false clause (he answered what she said she brought, not what she brought).

Clearly, Leon will profit from intensive speech and language therapy, but it may have a positive effect for his teachers to realize that despite the fact that he cannot make himself understood, he is quite advanced in his understanding of what others say to him.

\section{INDEPENDENCE OF LANGUAGE VARIATION AND DIAGNOSTIC STATUS}

It is especially difficult to be aware of linguistic strengths when the child uses stigmatized (i.e., non-MAE) word forms, such as doublemarked past tense ("he holded it") or an invariant case of a pronoun (as in "them boys" or "her going home"). These occur variably and are not predictable dialect forms, so their presence in a child's speech may be problematic. In cases such as these, the dialect-sensitive language test can highlight other sophisticated knowledge of the child that may not be evident in day-to-day conversation.

\section{Case Study 6: Dejean (Age 7 years, 1 months)}

\section{PROBABLE CONTRIBUTING FACTORS}

Developmental: No

Dialectal: Yes

Disordered: No

Dejean (Table 9) is a 7-year-old child from the south currently receiving language services in his school. His Screener Language Variation Status registers as "Some Variation from MAE," which alerts us to the appearance in his speech of predictable dialect forms that occur variably. That is, on the screener he used some features of MAE (e.g., "he has," "he talks"), and some features of AAE (e.g., "he don't," "he climb"). On the phonology items on the screener he produced some MAE forms

Table 9 Dejean (7 years, 1 months)-Summary of Scores

\begin{tabular}{|c|c|c|c|c|c|}
\hline \multicolumn{2}{|c|}{ Screening Items } & \multicolumn{4}{|c|}{ Comprehensive Language Test } \\
\hline $\begin{array}{l}\text { Language } \\
\text { Variation } \\
\text { Status }\end{array}$ & $\begin{array}{l}\text { Diagnostic } \\
\text { Risk } \\
\text { Status }\end{array}$ & Syntax & Pragmatics & Semantics & Phonology \\
\hline $\begin{array}{l}\text { Some } \\
\text { variation }\end{array}$ & Lowest & $\begin{array}{l}32 \\
\text { Strength }\end{array}$ & $\begin{array}{l}22 \\
\text { Strength }\end{array}$ & $\begin{array}{l}39 \\
\text { Strength }\end{array}$ & $\begin{array}{l}25 \\
\text { Strength }\end{array}$ \\
\hline
\end{tabular}


mixed with non-MAE forms. Indeed, in the responses that the examiner captured verbatim, in addition to many predictable dialect forms, we see elements that are immature, but not characteristic of a particular dialect (e.g., "them can't," "he hided it"); so he appears to be in the process of maturing as well as possibly learning to code-switch, but his learning is still incomplete.

In contrast to the uncertainty about his dialect status, he shows the lowest risk level on the diagnostic portion of the screener and his domain scores on the comprehensive language test are uniformly high. In fact, his domain scores are high enough to be considered "strengths" even if he were 2 years older. On the short narrative follow-up questions, for example, he made references to the characters' thoughts, putting his answers in the most mature category. (e.g., "She's thinking about the cake," "He didn't know his sister put it in the refrigerator"). Most children of his age would pass a theory of mind test (see P. de Villiers ${ }^{3}$ ), but fewer than half realize how important it is to include characters' thoughts and motivations in their stories and report them spontaneously, as Dejean did (Table 2).

In his wh-question asking, Dejean most often gave the right answer at the first prompt. In the three cases when he did not, he responded effectively to the examiner's prompt, even when it was indirect, as in recognizing, for example, that "for a reason" requires a why-question. Still more impressive is his ability on the fast mapping task. He did as well on the novel verbs as with the real verbs, demonstrating that he was truly processing the inflections -er, -ing, and other syntactic cues and did not rely on stored knowledge.

\section{Case Study 7: Nia \\ (Age 7 years, 8 months)}

\section{PROBABLE CONTRIBUTING FACTORS}

Developmental: Yes

Dialectal: No

Disordered: Yes

In contrast to Dejean, Nia (Table 10)—a 7-year-old African American child also from the south-uses enough MAE features to be categorized on the screener as an MAE speaker. She performed perfectly on the Phonology domain of the comprehensive language test and did very well at the nonword repetition task, missing only 1 of 6 , so we have an impression of a clear speaker with a good phonological memory. Her use of MAE surface inflections, however, does not mean that she commands the deep syntactic principles of the language.

In fact, Nia's diagnostic score for the screener indicates the highest level of risk. She used auxiliary is or are where a non-MAE speaker would generally omit them, but she used them in ways that revealed serious grammatical problems. For example, in the diagnostic portion of the screener, she used the present tense are (e.g., "the dogs are sleeping,") when the past tense verb were was called for. When asking questions in the pragmatics question asking items, she used the MAE is-copula with inversion (e.g., "What is it?"), but the poorly focused question failed to make reference to the action and objects highlighted in the prompt and the picture. Another of her responses was a well-formed, but irrelevant question (i.e., "Who made the cookies?")

Nia scored below the expectation for her age in three domains, most especially in Syntax.

Table 10 Nia (7 years, 8 months) - Summary of Scores

\begin{tabular}{|c|c|c|c|c|c|}
\hline \multicolumn{2}{|c|}{ Screening Items } & \multicolumn{4}{|c|}{ Comprehensive Language Test } \\
\hline $\begin{array}{l}\text { Language } \\
\text { Variation } \\
\text { Status }\end{array}$ & $\begin{array}{l}\text { Diagnostic } \\
\text { Risk } \\
\text { Status }\end{array}$ & Syntax & Pragmatics & Semantics & Phonology \\
\hline \multirow[t]{2}{*}{ Some variation } & Highest & 18 & 8 & 27 & 25 \\
\hline & & Weakness & Low average & Low average & Strength \\
\hline
\end{tabular}


On wh-comprehension items she produced four of the particular "red flag" responses that show difficulty with complex sentences, and four nonexhaustive responses to the double wh-items. For example, instead of answering both wh-items in "Who ate what?", she responded only to the "what" ("the pizza and the spaghetti") and neglected the "who" in all such items. In the passive items, she responded like a younger child, both in the number and kinds of errors, understanding the prompt as an active sentence three times and as a completed action rather than an ongoing event three times. Similarly, in the fast mapping, she did much better with the real verbs than the novel verbs, showing that she was not using the grammatical information present in the sentence well enough to answer correctly when there were no lexical clues.

This illustration shows how grammatical knowledge and dialect are independent of each other. Even among African American children, all levels of performance from the highest to the lowest are found in children who speak the mainstream dialect, and the same is true for those who show a strong variation from MAE.

\section{SUMMARY}

As can be seen by the case studies, the variations in children's language can be explained by the presence or absence of various factors: typical developmental patterns that reflect a child's maturation toward an adult grammar; dialectal patterns that reflect a child's cultural and linguistic community; and in some cases, patterns that indicate slow, delayed, or disordered development. When several of these factors are involved, as they often are, the diagnostic process is more complicated. Therefore, it is most important to have an assessment battery, such as the one proposed in this issue, that can help sort out the factors involved in the variations to ensure the appropriate placement of children in special programs.

\section{ACKNOWLEDGMENTS}

This work was funded in part by National Institutes of Health (NIDCD) under Contract
\#N01 DC8-2104 and Grant \#R01 DC 0217204 to Harry Seymour, Principal Investigator, at the University of Massachusetts Amherst, with Thomas Roeper and Jill de Villiers at the University of Massachusetts and Smith College, as co-investigators. It was accomplished in conjunction with The Psychological Corporation of Harcourt Assessment, Inc., San Antonio, TX.

The tests that are the products of this research collaboration are the Diagnostic Evaluation of Language Variation (DELV) assessments, the DELV Screening Test, DELV Criterion-Referenced edition, and the DELV Norm-Referenced edition. The phrase "evaluating language variation" refers generally to the assessment processes discussed in this issue. The term $D E L V$ is the name trademarked by The Psychological Corporation of Harcourt Assessments, Inc., and refers to the specific tests that are the outcome of the extensive reseach described in this article. The specific tests are referred to as the $D E L V-S T$, or "screener," or the $D E L V-C R, D E L V-N R$, or the "full diagnostic test," as appropriate. Questions about the principles underlying the tests can be referred to the authors of this issue (Seymour, Roeper, de Villiers, de Villiers, Pearson, and Ciolli). Questions about the tests themselves should be addressed to the Project Leader at The Psychological Corporation of Harcourt Assessment, Inc.; Lois Ciolli, Senior Research Director.

\section{REFERENCES}

1. Seymour HN, Pearson ZP. Steps in designing and implementing an innovative assessment instrument. Semin Speech Lang 2004;25:27-32

2. Roeper T. Diagnosing language variations: underlying principles for syntactic assessment. Semin Speech Lang 2004;25:41-56

3. de Villers P. Assessing pragmatic skills in elicited production. Semin Speech Lang 2004;25:57-72

4. de Villers JG. Cultural and linguistic fairness in the assessment of semantics. Semin Speech Lang 2004; 25:73-90

5. Seymour HN. A noncontrastive model for assessment of phonology. Semin Speech Lang 2004;25: 91-100 